\title{
SERÁ O FALTA DE SIMBIOSE ENTRE INDÚSTRIA E SERVIÇOS INTERMEDIÁRIOS A CAUSA DA ESTAGNAÇÃO ECONÔMICA BRASILEIRA?
}

\author{
Adilson Giovanini ${ }^{1}$ \\ Marcelo Arend ${ }^{2}$
}

\begin{abstract}
Resumo
A literatura de serviços mostra que os países desenvolvidos apresentam uma relação de simbiose entre serviços intermediários e o setor industrial. O objetivo deste estudo é identificar se os serviços intermediários contribuíram para o crescimento do PIB nacional e da indústria brasileira no período 19702009. A metodologia proposta por Toda e Yamamoto foi utilizada para testar a presença de causalidade no sentido sugerido por Granger entre o crescimento do setor de serviços e o crescimento do industrial. Os resultados encontrados evidenciam a existência de simbiose entre indústria e serviços intermediários. Eles também mostram que o setor de serviços intermediários causa o crescimento do PIB brasileiro e do valor adicionado industrial, enquanto que o crescimento do setor de industrial não contribui para o crescimento do PIB. Paradoxalmente, o crescimento do setor de serviços intermediários consegue induzir um processo autossustentado de crescimento econômico, sendo o mesmo não observado para o setor industrial. $\mathrm{O}$ fato de o setor industrial não contribuir para o crescimento do PIB pode levar a conclusão de que o problema brasileiro se encontra na indústria e não no setor de serviços intermediários. A visão aqui defendida é que o problema é mais complexo, e a estagnação brasileira pode ser resultado de uma falta de simbiose entre ambos os setores. A importância dos serviços intermediários aumentou nas últimas décadas com a emergência do novo paradigma tecnoeconômico, porém a presença em território nacional de serviços de menor qualidade comprometeu a competitividade industrial.

Palavras Chaves: mudança estrutural; serviços intermediários; simbiose industrial; Brasil

JEL: L16; L22; L84; L86; O40

Área: Crescimento, produtividade e competitividade
\end{abstract}

\begin{abstract}
The service literature shows that developed countries have a symbiosis relationship between intermediate services and the industrial sector. The objective of this study is to identify if the intermediary services contributed to the growth of national GDP and Brazilian industry in the period 1970-2009. The methodology proposed by Toda and Yamamoto was used to test the presence of causality in the sense suggested by Granger between the growth of the service sector and the growth of the industry. The results show the existence of symbiosis between industry and intermediary services. They also show that the intermediate services sector causes Brazilian GDP growth and industrial added value, while the growth of the industrial sector does not contribute to GDP growth. Paradoxically, the growth of the intermediary services sector is able to induce a self-sustaining process of economic growth, and the same is not observed for the industrial sector. The fact that the industrial sector does not contribute to GDP growth can lead to the conclusion that the Brazilian problem lies in the industry and not in the intermediary services sector. The view defended here is that the problem is more complex, and Brazilian stagnation may be the result of a lack of symbiosis between the two sectors. The importance of intermediary services has increased in recent decades with the emergence of the new techno-economic paradigm, but the presence of lower-quality services in Brazil has compromised industrial competitiveness.
\end{abstract}

Keywords: economic growth; Intermediate services; Symbiosis; Brazil

\footnotetext{
${ }^{1}$ Doutorando Programa de Pós-graduação em Economia -PPGECO/UFSC, adilsoneconomia@gmail.com

${ }^{2}$ Professor Adjunto do Departamento de Economia e Relações Internacionais - UFSC, marcelo.arend@ufsc.br
} 


\section{INTRODUÇÃO}

O presente artigo procura contribuir para a melhor compreensão do desenvolvimento econômico brasileiro no período pós 1980. É praticamente consenso entre pesquisadores e historiadores econômicos que nas últimas três décadas a economia brasileira apresentou reduzido desempenho em termos de elevação da produtividade do trabalho (DE NEGRI, 2014; KON, 2015). Em linhas gerais, o estancamento da produtividade nacional esteve relacionado com o processo de mudança estrutural, marcadamente pelos ganhos de participação no produto e na renda do setor de serviços em detrimento do setor industrial (ARBACHE, 2012). Nestes termos, o presente artigo objetiva melhor elucidar esse processo de mudança estrutural, através da análise da relação dinâmica existente em o setor industrial e de serviços.

A literatura clássica de desenvolvimento econômico e de mudança estrutural mostra que o setor industrial é capaz de promover movimentos autodeterminados de crescimento econômico. Os países que conseguem migrar para setores industriais mais sofisticados, num processo constante de transformação produtiva, aceleram suas taxas de crescimento econômico, em detrimento dos demais países ${ }^{3}$. Entretanto, evidências empíricas mais recentes mostram que o setor de serviços intermediários também contribui para o surgimento de inovações, mudança estrutural e aumento da produtividade industrial ${ }^{4}$. Serviços avançados fornecem conhecimentos tecnológicos demandados, principalmente, pelas atividades industriais mais sofisticadas, pois uma parte considerável das inovações que emergiram a partir da década de 1980 partiu dos serviços intermediários e sua interação com a indústria ${ }^{5}$. De modo que os serviços explicam cada vez mais a inserção dos países nas cadeias globais de valor ${ }^{6}$.

Diversos estudos buscaram elencar as características apresentadas pelo setor de serviços no Brasil. Arbache $(2012,2014,2015 \mathrm{a}, 2016)$ mostra que este setor é caracterizado pela presença de empresas pequenas, pouco financiadas, mal equipadas, mal geridas e com baixa produtividade. Ele possui participação muito elevada no PIB e no valor adicionado industrial, comparado a outros países, apresentando regulamentação excessiva; baixa produtividade, concorrência, qualidade e disponibilidade; e preços elevados. As características deste setor em território nacional - ausência de serviços mais sofisticados, baixa produtividade, baixa qualidade e preços elevados - ajudam a explicar a fraca produtividade agregada e a baixa competitividade da indústria nacional. Além disto, o setor de serviços brasileiro representa uma anomalia, pois a partir de 1985 a sua participação no valor adicionado cresceu de forma exagerada, sendo este crescimento puxado, principalmente, por serviços finais - pelo setor financeiro e de administração, saúde e educação - (ARBACHE, 2015b) e não por serviços intermediários e que contribuem para o aumento da competitividade industrial (OULTON, 2001). A realização de reformas - desregulamentação; aumento da competitividade; e acesso a novas tecnologias - se mostra medida cada vez mais necessária para que o país volte a ser competitivo.

Ademais, Corrêa (2016) mostra que os países asiáticos estão se inserindo nas cadeias globais de valor através de políticas voltadas para o desenvolvimento tecnológico e do setor de serviços intermediários. Por outro lado, o Brasil pertence a um grupo de países que ingressa nas cadeias globais de valor apenas através da exportação de produtos naturais, o que o deixa sensível às mudanças de curto prazo nos termos de troca. Assim, a baixa presença de serviços de alta qualidade (curva sorridente) ajuda a explicar a baixa inserção do país nas cadeias globais de valor.

Dada esta contextualização, a problemática deste estudo parte das novas evidências encontradas pela literatura internacional que advogam por uma elevada simbiose entre indústria e serviços para a promoção do desenvolvimento. Apesar de existir uma vasta quantidade de evidências empíricas internacionais que mostram que os serviços intermediários contribuem para o crescimento econômico e que identificam a existência de uma relação de simbiose entre serviços intermediários e indústria, não encontramos nenhum estudo que buscasse identificar se esta relação se encontra presente na economia brasileira. Assim, o objetivo deste estudo é verificar se o crescimento do setor de serviços intermediários

\footnotetext{
${ }^{3}$ Lewis (1954), Kuznets (1955, 1957, 1973), Hirschman (1958), Kaldor (1966)

${ }^{4} J o r g e n s o n$ (2008), Lesher e Nordås (2006), Franke e Kalmbach (2005), Triplett e Bosworth (2003, 2004), Park e Chan (1989), Markusen (1989)

${ }^{5}$ Miles Et Al. (1994, 1995, 2008); Hertog (2000); Muller,(2001); Czarnitzki e Spielkamp (2000)

${ }^{6}$ Shih (1992); OCDE/OMC (2013, p. 216); Nordås, 2008; Nordås e Kim (2013)
} 
explica o crescimento do PIB e do setor industrial brasileiro, sendo este mensurado em termos de crescimento do valor adicionado, da produtividade e do valor adicionado per capita. Ademais, também se identifica se o crescimento do setor industrial brasileiro contribui para o crescimento do setor de serviços intermediários, em termos de valor adicionado.

A hipótese defendida é que tanto o setor industrial quanto o setor de serviços defrontam-se com aguda estagnação relativa internacional e inércia estrutural, comprometendo o desempenho da economia brasileira. Ou seja, a precariedade de uma relação de simbiose entre serviços e indústria restringe a transformação da economia brasileira em direção a setores tecnologicamente mais avançados e produtivos. A reduzida virtuosidade desta relação compromete a produtividade da indústria nacional e o crescimento econômico.

A metodologia proposta por Toda e Yamamoto (1995) será utilizada para estimar modelos VAR em painel. Posteriormente, serão aplicados testes modificados de Wald para identificar a presença de causalidade no sentido proposto por Granger (MADDALA, 1992). Todas as estimações são realizadas para dados do período 1980-2009.

Os resultados encontrados indicam que o crescimento do setor de serviços intermediários causa Granger o crescimento do PIB e do valor adicionado da indústria Brasileira. Este teste também indica que o crescimento do setor de serviços intermediários causa Granger o crescimento do valor adicionado per capita e da produtividade do setor industrial. Por outro lado, o crescimento do valor adicionado do setor industrial não causa Granger o crescimento do PIB, enquanto que o crescimento dos serviços intermediários causa Granger o crescimento do PIB. Nesse sentido, nossos resultados apontam para uma potencial debilidade do setor industrial brasileiro para incitar um processo kaldoriano de crescimento econômico. Percebemos que o padrão de relativa estagnação da economia brasileira, no período em tela, deve-se a dois fatores que revelam uma reduzida simbiose entre indústria e serviços: 1) $O$ fraco desempenho relativo da indústria brasileira em relação a suas congêneres internacionais, bem como a sua inércia estrutural, manifestada pela não diversificação produtiva em direção a bens mais sofisticados tecnologicamente. A relativa estagnação industrial, aliada a sua inércia estrutural, desestimula o desenvolvimento dos serviços intermediários e, consequentemente, impacta para a manutenção no longo prazo de reduzidas taxas de crescimento econômico; 2) Os impactos deletérios sobre o setor industrial dos serviços de custos e de valor, que diminuem a competitividade e dificultam a instituição de um processo de mudança estrutural na economia brasileira.

Além desta introdução este artigo possui mais cinco seções. A seção 2 mostrará as novas evidências encontradas pela literatura de serviços intermediários. Em seguida, a seção 3 apresentará a metodologia utilizada no teste estatístico que busca captar a relação de simbiose entre indústria e serviços na economia brasileira. Posteriormente, a seção 4 consolidará os resultados obtidos. A seção 5 apresentará indicadores de desempenho internacional da indústria e dos serviços intermediários, bem como um diagnóstico da estrutura industrial e de serviços do Brasil, com vistas a melhor compreender os resultados. Por fim, a seção 6 apresentará as considerações finais.

\section{A CONTRIBUIÇÃO DA INDÚSTRIA E DOS SERVIÇOS INTERMEDIÁRIOS PARA O CRESCIMENTO ECONÔMICO}

Inicialmente, a literatura econômica defendia que o crescimento econômico era explicado pela mudança na composição setorial das economias. O crescimento econômico era percebido como o resultado da migração do setor tradicional (agricultura) para o setor moderno (indústria) ${ }^{7}$. Estes estudos defendiam que o estímulo do processo de mudança estrutural em direção a ganhos de participação da indústria na renda nacional era capaz de conduzir as economias para trajetórias de crescimento econômico sustentado. Em especial, Kaldor (1966) defendia a capacidade da indústria em promover um processo autodeterminado de crescimento econômico.

\footnotetext{
${ }^{7}$ Lewis (1954); Kuznets (1955, 1957, 1973);
} 
Kaldor (1966) argumentou que a indústria é heterogênea e que os países passam por quatro etapas específicas de industrialização: 1) inicialmente os países produzem bens industriais básicos de consumo; 2) posteriormente passam a exportar estes bens; 3) na terceira etapa, eles produzem bens de capital; 4) por fim, eles se tornam exportadores líquidos de bens de capital minimizando inclusive problemas relativos a restrição externa ao crescimento. Ademais, Kaldor (1966) argumenta que, conforme os países migram para as fases mais avançadas, a taxa de crescimento econômico se acelera.

Hoffmann (citado por Sutcliffe, 1971, p. 33) também mostrou que as atividades industriais não surgem em determinado espaço produtivo de forma aleatória. Inicialmente surgem atividades com baixo nível de sofisticação tecnológica, relacionadas à produção de bens de consumo (alimentos, têxteis, couro e móveis). Posteriormente, emergem atividades mais sofisticadas, associadas à indústria de bens de capital (metal-mecânico, química avançada). A importância da indústria é enfatizada ainda mais por Hirschman (1958), que defende o incentivo aos setores industriais que possuem fortes encadeamentos para trás e para frente (linkages) como estratégia de desenvolvimento econômico.

Conforme será visto na sequência, a partir da década de 1990 surgiram novas evidências na literatura econômica internacional que não reservam somente ao setor industrial a função de motor do desenvolvimento econômico. Estas mostram que os serviços intermediários também influenciam nas trajetórias de desenvolvimento. A irrupção de tecnologias disruptivas relativas ao novo paradigma tecnoeconômico (Perez, 2004) que emergiu nas décadas de 1970-80 contribuiu para a ocorrência de diversas modificações na dinâmica econômica, dentre as quais se destacam: aumento no comércio de serviços; crescimento dos serviços de negócios relacionados à gestão das cadeias globais de valor; terceirização e offshore. Todos estes fatores contribuíram para o crescimento dos serviços intermediários; surgimento de novas atividades; maior especialização e aumento da produtividade. Também, parte substantiva do aumento de produtividade das economias que melhor se inseriram no novo paradigma foi repassado para a indústria ${ }^{8}$.

A terceirização de atividades tecnológicas e produtivas para firmas cada vez mais especializadas em serviços estimulou o crescimento do setor e o seu crescimento viabilizou a maior especialização produtiva, o aumento da produtividade do trabalho e o surgimento de um novo leque de serviços intermediários, resultando na formação de um circulo virtuoso de crescimento, terceirização, especialização e ganho de produtividade ${ }^{9}$. Serviços mais produtivos e de elevada qualidade implicaram em bens industriais mais baratos e de melhor qualidade, resultando em maior competitividade dos países que os produzem ${ }^{10}$.

Deste modo, a realização de inovações nos serviços intermediários elevou a produtividade das firmas e isto contribuiu para o surgimento de inovações, formando-se um ciclo virtuoso. A força desta relação é crescente, pois quanto maior for o desempenho de uma firma de serviços maior será o seu incentivo a inovar e quanto mais ela inova mais o seu desempenho se eleva (CAINELLI et al., 2006). Ademais, há fortes evidências de que os serviços de negócios estão sujeitos às leis de Kaldor, também sendo capazes de provocar crescimento autossustentado (DI MEGLIO et al., 2015; DASGUPTA e SINGH, 2007).

Os serviços passaram a ser associados à capacidade de inovação dos países (MIOZZO e SOETE, 2001). A literatura de serviços intensivos em conhecimento (KIBS) mostra que este setor supre a indústria com o conhecimento necessário à realização de inovações. Estes conhecimentos surgem da interação entre serviços e indústria e não de atividades específicas encontradas isoladamente em apenas um destes setores (MILES et Al., 1994, 1995, 2008; HERTOG, 2000; MULLER, 2001; CZARNITZKI e SPIELKAMP, 2000).

\footnotetext{
${ }^{8}$ Freund e Weinhold (2002); Motohashi (1997); Bhagwati (1984); Hoekman e Primo Braga (1997); Franke e Kalmbach (2005); Lesher e Nordås (2006); Rodrigue (2006); Bryson Et. Al (2004); Lesher e Nordås (2007); Miozzo e Soete (1999); Francois e Woerz (2008); Berlingieri (2013); Gereffi e Frederick (2010); Maroto-Sanches e Cuadrado-Roura (2011); Jorgenson e Timmer (2011).

${ }^{9}$ Jorgenson (2008); Lesher e Nordås (2006); Franke e Kalmbach (2005); Triplett e Bosworth (2003); Triplett e Bosworth (2004); Park e Chan (1989); Markusen (1989).

${ }^{10}$ Berlingieri (2013); Amiti e Wei (2005); Francois e Woerz (2008); Carter (1970) e Barker e Forssell (1992).
} 
As evidências que mostram que os serviços intermediários contribuem para o surgimento de inovações na indústria levaram Castellacci (2008) a construir uma nova taxonomia relativa ao novo paradigma tecnoeconônico que irrompeu na década de 1980. Esta possui como base Pavitt (1984) e, diferente de Miozzo e Soete (2001), considera a interação serviços-indústria.

Castellacci dividiu as atividades em quatro grupos: Fornecedores de conhecimento avançado: possuem capacidade tecnológica elevada e são provedores de conhecimento para outros setores,sendo discriminadas em: 1) firmas industriais especializadas em máquinas e equipamentos de precisão; e 2) firmas de serviços especializadas em soluções técnicas e conhecimentos tecnológicos como P\&D, software, engenharia e consultoria. Fabricação de produtos em Massa: fabricam bens industriais finais e intermediários e que possuem elevada capacidade de desenvolvimento de produtos e processos internamente e através de cooperação externa. Serviços de Infraestrutura de apoio: produzem bens e serviços intermediários. A inovação ocorre através da aquisição de máquinas, equipamentos e diversas formas de conhecimento tecnológico. Bens e Serviços Pessoais: possuem baixo conteúdo tecnológico e limitada capacidade de desenvolvimento de novos produtos e processos. A inovação ocorre através da aquisição de máquinas, equipamentos e serviços de outros setores.

As evidências encontradas pela literatura de serviços permitem complementar a análise realizada por Kaldor (1966). A migração para atividades industriais mais sofisticadas acelera as taxas de crescimento econômico. Contudo, os serviços intermediários e a indústria são interdependentes, sendo o desenvolvimento conjunto destes setores que resulta em maior crescimento. Ou seja, a indústria demanda o desenvolvimento de soluções específicas oriundas de serviços. Em caráter complementar, as inovações nos serviços provocam mudanças na indústria de transformação e demandam o surgimento de novas atividades industriais e de serviços (GALLOUJ; WEINSTEIN, 1997; WINDRUM; TOMLINSON, 1999; DI CAGNO; GUERRIERI; MELICIANI, 2005).

Nordås (2010) mostrou que indústrias que possuem elevado conteúdo tecnológico são mais intensivas em serviços do que as demais. O aumento na participação do setor de serviços como insumo utilizado pela indústria faz com que este setor se transforme no principal vetor de dinamismo econômico. O seu crescimento determina o crescimento da produtividade industrial e do PIB (LINDEN et al, 2011; KENDRICK, 1985 e NORDÅS e KIM, 2013).Os ganhos de produtividade obtidos pelo setor de serviços também se tornam cada vez mais importantes para garantir a geração de empregos e o pagamento de salários elevados. Por outro lado, o não desenvolvimento desse setor pode criar entraves que restringem a capacidade de crescimento econômico dos países (KENDRICK, 1985).

Ademais, Imbs e Wacziarg (2003) mostraram que os países diversificam suas estruturas produtivas conforme suas rendas aumentam. Em complemento, Hausmann e Kilinger (2007) argumentaram que a diversificação ocorre através da migração das firmas para produtos que demandam capacitações (conhecimentos) semelhantes. Posteriormente, a literatura de complexidade econômica encontrou evidências que corroboram estes argumentos. ${ }^{11}$ A literatura da complexidade econômica mostra que o desenvolvimento econômico é produto específico, o que indiretamente indica que os países devem realizar políticas de mudança estrutural setores-específicos para realizar catchingup. A realização destas políticas foi defendida por Rodrik e Mukand (2017).

Essas novas evidências levaram Nübler (2014) a desenvolver o conceito de comunidades de conhecimento e a argumentar que a presença de capacitações associadas à capacidade de aprendizado dos países determina a realização de processos de catching up. Os países devem estimular suas fïmas a migrarem para comunidades de conhecimento maiores e com mais ligações inter e intra setoriais. Ancorados na literatura de serviços acima exposta, defendemos que a migração para estas comunidades com maior complexidade produtiva demanda o surgimento de serviços intermediários, o que contribui para o crescimento e diversificação do setor industrial.

Em suma, as evidências apresentadas pela literatura econômica contemporânea estão mostrando que a quantidade de conhecimento produtivo possuída pelos países e as suas capacidades em expandir estes conhecimentos e vinculá-los ao setor industrial determinam a sua capacidade de crescimento. Os serviços intermediários fornecem conhecimentos tecnológicos vitais ao setor industrial, acelerando o

${ }^{11}$ Hidalgo et al (2007); Hidalgo e Hausmann (2009); Hausmann e Hidalgo (2011); Hausmannet al.(2014); Klimek et al (2012) 
crescimento do PIB. O não desenvolvimento destes serviços significa a não oxigenação do setor industrial com conhecimentos tecnológicos necessários. Como resultado, o país não consegue diversificar a sua estrutura produtiva, restringindo seu processo de mudança estrutural e, em termos internacionais, permanecendo defasado tecnologicamente e com baixa produtividade relativa.

\section{METODOLOGIA}

\subsection{Dados utilizados}

Os dados de estoque de capital, disponibilizado pelo Pen World Table, Feenstra et al. (2015) e os dados de produção e produtividade setoriais, extraídos do Groningen Growth and Development Centre (GGDC), Timmer et al. (2015),foram utilizados para estimar alguns modelos VAR em painel para o período 1980-2009.

Um problema enfrentado ao se utilizar esta base de dados se refere à definição do setor de serviços intermediários, dos cinco setores de serviços discriminados pelo GGDC, apenas dois foram classificados como serviços intermediários: 1) Transportes, Armazenagem e Comunicação e 2) Intermediação financeira, arrendamento e serviços empresariais ${ }^{12}$. Ademais, com o objetivo de eliminar a relação de curto prazo existente entre as variáveis (ciclo econômico), as regressões serão estimadas com base na taxa de crescimento média para cada seis anos de cada variável.

\subsection{A metodologia de Toda e Yamamoto}

A literatura econométrica (eg. Stock e Watson, 2001) normalmente recomenda a utilização de modelos Vetor Autorregressivo (VAR) em painel para a realização de testes de causalidade. O problema é que estes modelos exigem que todas as séries possuam a mesma ordem de integração, não podendo ser aplicados quando os testes de estacionariedade indicam que as séries apresentam ordem de integração diferente. O procedimento proposto por Toda e Yamamoto (1995) elimina este problema.

Esse procedimento utiliza um número de defasagens superior ao ótimo (indicado pelos critérios de informação). Isto torna o modelo mais robusto e possibilita a utilização de informações sobre as séries em nível, que não seriam consideradas. O procedimento proposto por Toda e Yamamoto pode ser decomposto em três passos: 1) definição do número ótimo de defasagens, $h$, e da ordem máxima de integração do sistema, d; 2) estimação do modelo VAR em painel; e 3) teste das restrições de Wald para os $h$ primeiros coeficientes para testar a hipótese de não causalidade de Granger.

O primeiro passo consiste em aplicar o teste de Dickey-Fuller aumentado para identificar se as séries são estacionárias. Este teste parte da seguinte equação:

$$
\Delta y_{t}=a_{1}+a 2 t+\rho_{i} y_{t}+\sum_{j=1}^{m} \theta_{j} y_{t-1}+\xi_{t}
$$

em que $a_{1}$ é o intercepto; $a_{2}$ é o coeficiente da tendência; $\rho_{i}$ é o coeficiente da primeira raiz unitária; $m$ é o número de defasagens; e $\xi_{t}$ é um efeito aleatório. Na equação (1) se testa a hipótese nula H0: $\rho_{i}=0$ com base na estatística $t=\frac{\widehat{\rho}_{i}}{s e\left(\widehat{\rho}_{i}\right)}$, sendo $\hat{\rho}_{i}$ um estimador para $\rho_{i}$ e $s e\left(\hat{\rho}_{i}\right)$ um estimador para o desvio padrão.

Como alternativa, a presença de estacionariedade é testada com base no teste de Kwiatkowski, Phillips, Schmidt e Shin (KPSS). O teste KPSS (SHIN, 1992) possui a hipótese nula de que o processo estocástico $\mathrm{y}_{\mathrm{i}, \mathrm{t}}$ é estacionário, sendo aplicado com base no seguinte modelo:

$$
y_{t}=a_{1}+a 2 t+\xi_{t}+e_{t}
$$

\footnotetext{
${ }^{12}$ Os serviços não incluídos como serviços intermediários são: Eletricidade, gás e água; Construção; Comercio no atacado e varejo; reparação de veículos automóveis, motociclos e bens de uso pessoal e doméstico, hotéis e restaurantes; Administração Pública e Defesa, Educação, Saúde e ação social; e Outros serviços comunitários, atividades de serviços pessoais e sociais e, Atividades domésticas privadas.
} 


$$
\xi_{t}=\xi_{t-1}+u_{t}
$$

em que $u_{t} \sim$ i.i.d. $\left(0, \sigma_{u}^{2}\right)$, sendo $e_{t}$ um processo estacionário. A estatística de teste é definida como: $L M=\frac{\sum_{i=1}^{n} S_{t}^{2}}{\sigma_{e}^{2}}$, em que $S_{t}^{2}$ é a soma dos quadrados do resíduo de uma regressão de $y_{t}$ contra um intercepto e uma tendência; $\sigma_{e}^{2}$ é a soma do quadrado dos resíduos da regressão dividido por $n$; e $n$ é o número de observações do processo estocástico.

No segundo passo o número ótimo de defasagens é identificado através do critério de informação de Akaike (AIC), proposto por Bozdogan (1987), e do critério de informação Bayesiano (BIC), proposto por Schwarz (1978). O AIC é formalmente definido como: $A I C=-2 \log L(\theta)+2(p)$, em que $L(\theta)$ é a funçãomaximizada; $\mathrm{p}$ é o número de parâmetros estimados e $n$ é o número de observações. (McQuarrie; Tsai, 1998). Já o BIC é definido como: $\mathrm{BIC}=-2 \log f\left(x_{n} \mid \theta\right)+\mathrm{p} \log n, \operatorname{sendo} f\left(x_{n} \mid \theta\right)$ o modelo escolhido.

O terceiro passo consiste em estimar um teste de Granger em bloco com $d$ defasagens a mais do que o número ótimo, $h$, indicado pelos critérios de informação AIC e BIC. Em que $d$ é a ordem máxima de integração das variáveis do modelo VAR, indicado pelo teste de Dickey-Fuller.Deste modo, Toda e Yamamoto estimam o seguinte modelo VAR para detectar a presença de causalidade no sentido proposto por Granger entre as séries temporais.

$$
\begin{aligned}
& X_{i t}=\alpha_{1}+\sum_{l=1}^{h+d} \beta_{1 l} X_{i, t-k}+\sum_{l=1}^{h+d} \gamma_{1 l} Y_{i, t-k}+\varepsilon_{1 i t}, \\
& Y_{i t}=\alpha_{1}+\sum_{l=1}^{h+d} \beta_{2 l} Y_{i, t-k}+\sum_{l=1}^{h+d} \gamma_{2 l} X_{i, t-k}+\varepsilon_{2 i t},
\end{aligned}
$$

em que $\varepsilon_{1 i t}$ e $\varepsilon_{2 i t}$ são ruídos brancos; e $X_{i t}$ e $Y_{i t}$ são processos estocásticos.Para a equação (4) as hipóteses testadas são:H0: $Y_{i t}$ não causa Granger $X_{i t}$, se $\sum_{l=1}^{h} \gamma_{11}=0 ; H 1: Y_{i t}$ causa Granger $X_{i t}$, se $\sum_{\mathrm{l}=1}^{\mathrm{h}} \gamma_{11} \neq 0$, e para a equação (5) são:H0: $X_{\text {it }}$ não causa Granger $Y_{i t}$, se $\sum_{\mathrm{l}=1}^{\mathrm{h}} \gamma_{21}=0$; H1: $X_{\text {it }}$ causa Granger $Y_{i t}$, se $\sum_{\mathrm{l}=1}^{\mathrm{h}} \gamma_{21} \neq 0$.

Toda e Yamamoto (1995) sugerem a utilização de um teste de Wald modificado (MWald), no qual são testadas restrições impostas nos parâmetros do modelo VAR. Elesmostraram que em sistemas integrados ou cointegrados o teste de Wald para restrições lineares nos parâmetros de um VAR possui distribuição assintótica chi-quadrado $\left(\mathrm{x}^{2}\right)$, independente de o sistema ser estacionário. $\mathrm{O}$ teste de restrições de Wald para a hipótese de não causalidade de Granger é realizado somente nos hprimeiros coeficientes, os últimos dcoeficientes são adicionados ao modelo comovariáveis exógenas. Essas defasagens adicionais são necessárias para garantir que a estatística de teste possua distribuição assintótica chi-quadrado $\left(\mathrm{x}^{2}\right)$.

\section{RESULTADOS ENCONTRADOS}

A Tabela 2 apresenta o valor encontrado para o teste de estacionariedade de Dickey-Fuller e KPSS. Conforme se observa, o teste de Dickey-Fuller indica que todas as variáveis são estacionárias em primeira diferença. As únicas exceções são o estoque de capital e o PIB que são estacionários em nível. Por outro lado, o teste KPSS indica que todas as variáveis são estacionárias em nível, exceto o estoque de capital que é estacionário em segunda diferença. Dado que há discordância entre os testes, realiza-se o procedimento sugerido por Toda e Yamamoto com base nos resultados encontrados para o teste KPSS. Isto é, $d=2$.

Tabela 2 - Teste de estacionariedade, Dickey-Fuller aumentado

\begin{tabular}{ccccccccccccc}
\hline Variável & $\begin{array}{c}\text { ADF } \\
\text { aumentado }\end{array}$ & alor & pv & & KP & Var & $\begin{array}{c}\text { ADF } \\
\text { aumentado }\end{array}$ & valor & PSS & K \\
\hline
\end{tabular}




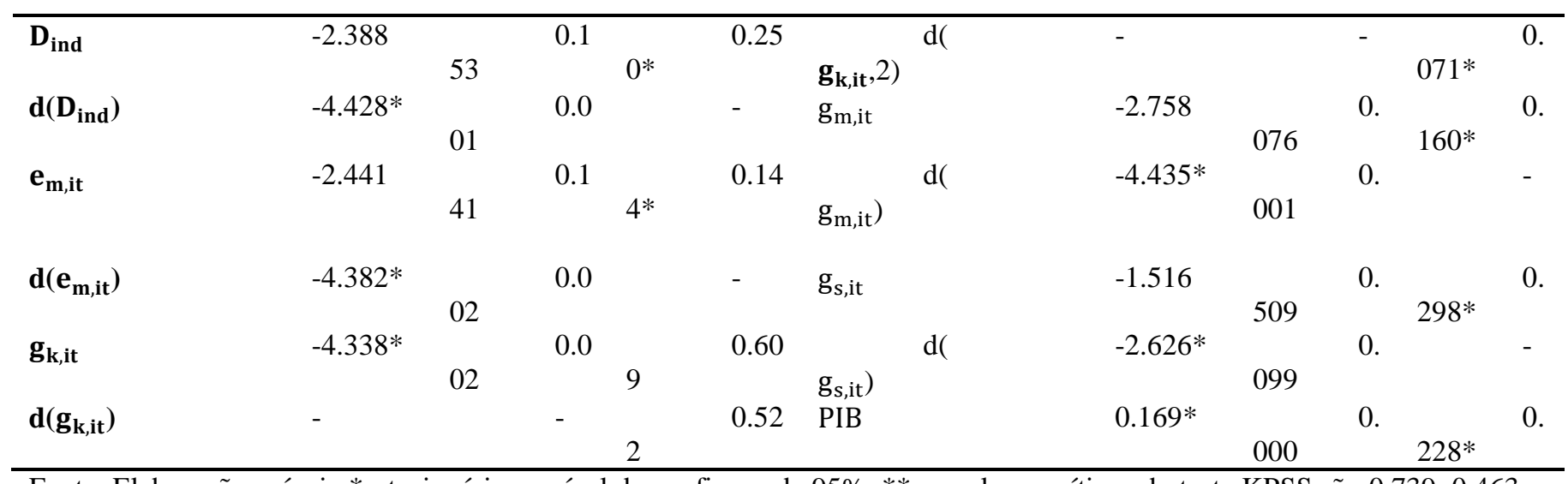

Fonte: Elaboração própria *estacionária ao nível de confiança de 95\%, ** os valores críticos do teste KPSS são 0.739; 0.463; e 0.347 , para os níveis de confiança de $99 \%$; $95 \%$ e $90 \%$, respectivamente.

Os resultados consolidados na Tabela 3 para o critério de informação de Schwarz indicam que o modelo VAR deve ser estimado com 1 defasagem. Assim, este modelo é estimado com a adição de três defasagem, uma endógena, para o período t-1, e duas exógenas, para os períodos t-2 e t-3, com o objetivo de cumprir os requisitos exigidos pelo procedimento proposto por Toda e Yamamoto. $O$ teste de correlação de Portmanteau mostra que o resíduo não apresenta autocorrelação, de modo que os coeficientes estimados são válidos e o modelo VAR explica o comportamento apresentado pelas variáveis em tela. O teste de MWald evidencia que o crescimento do valor adicionado do setor de serviços intermediários causa Granger o crescimento do PIB. O crescimento do setor industrial não contribui para o crescimento do PIB. O crescimento do valor adicionado do setor de serviços intermediários causa Granger o crescimento do valor adicionado industrial. Os crescimentos do valor adicionado do setor industrial, do PIB e do estoque de capital causam Granger o crescimento do valor adicionado do setor de serviços. Ademais, o crescimento do valor adicionado do setor de serviços intermediários causa o crescimento do estoque de capital.

Tabela 3 - Resultados encontrados, procedimento de Toda e Yamamoto, período 1980-2009, PIB

\begin{tabular}{|c|c|c|c|c|c|}
\hline \multicolumn{6}{|c|}{ Modelo PIB $\mathbf{g}_{m, \mathbf{i t}} \mathbf{g}_{\mathrm{s}, \mathrm{it}} \mathbf{g}_{\mathbf{k}, \mathbf{i t}}$} \\
\hline \multicolumn{3}{|c|}{ Variável dependente: PIB } & \multicolumn{3}{|c|}{ Variável dependente: $\mathbf{g}_{\mathbf{m}, \text { it }}$} \\
\hline Excluída & Qui quadrado & $\operatorname{Pr}$ & Excluída & Qui quadrado & $\operatorname{Pr}$ \\
\hline $\mathbf{g}_{\mathbf{m}, \mathrm{it}}$ & 1.825 & 0 . & PIB & 1.974 & 0. \\
\hline$g_{s, i t}$ & $8.011 *$ & 0 . & $\mathbf{g}_{\mathrm{s}, \mathrm{it}}$ & $5.237^{*}$ & 0 . \\
\hline$g_{k, i t}$ & 0.687 & 0. & $\mathbf{g}_{\mathrm{k}, \mathrm{it}}$ & 0.451 & 0 . \\
\hline \multicolumn{3}{|c|}{ Variável dependente: $\mathbf{g}_{\mathbf{s}, \mathbf{i t}}$} & \multicolumn{3}{|c|}{ Variável dependente: $\mathbf{g}_{\mathbf{k}, \mathbf{i t}}$} \\
\hline Excluída & Qui quadrado & $\operatorname{Pr}$ & Excluída & Qui quadrado & $\operatorname{Pr}$ \\
\hline PIB & $8.165^{*}$ & 0 . & PIB & 0.169 & 0. \\
\hline $\mathbf{g}_{\mathrm{m}, \mathrm{it}}$ & $6.714 *$ & 0 . & $\mathbf{g}_{\mathrm{m}, \mathrm{it}}$ & 0.000 & 0 . \\
\hline $\mathbf{g}_{\mathbf{k}, \mathbf{i t}}$ & $2.921 * *$ & 0 . & $\mathrm{g}_{\mathrm{s}, \mathrm{it}}$ & $3.438 * *$ & 0 . \\
\hline $\operatorname{AIC}(3)$ & -35.00 & & & & \\
\hline $\operatorname{BIC}(1)$ & -32.56 & & & & \\
\hline Portmanteau & 34.91 & & & & \\
\hline
\end{tabular}

Fonte: Elaboração própria, * significativo ao nível de confiança de 95\%, ** significativo ao nível de confiança de 90\%

Esses resultados indicam que o setor de serviços contribui consideravelmente para o crescimento do PIB e do valor adicionado do setor industrial. Contudo, o mesmo não pode ser afirmado para o setor industrial. $\mathrm{O}$ crescimento deste setor não consegue estimular o crescimento do setor de serviços com a mesma força. Identifica-se, assim, uma baixa relação de causalidade entre estes setores.

Os resultados consolidados na Tabela 4 para o critério de informação de Schwartz indicam que o modelo VAR para a produtividade industrial deve ser estimado com apenas uma defasagem. Assim, estima-se o modelo com uma defasagem endógena e duas defasagens adicionais exógenas, períodos t-2 e t-3, conforme exigido pelo procedimento de Toda e Yamamoto. Os resultados encontrados para o teste de autocorrelação de Portmanteau indicam que o resíduo não apresenta autocorrelação. $\mathrm{O}$ teste de MWald 
mostra que apenas o crescimento do valor adicionado industrial contribui para o crescimento da produtividade deste setor. $\mathrm{O}$ crescimento do valor adicionado do setor de serviços não causa Granger o crescimento da produtividade industrial. Deste modo, não se observa a formação de uma relação de simbiose entre estes setores, o que pode explicar, ao menos em parte, as baixas taxas de crescimento apresentadas pelo Brasil.

Tabela 4 - Resultados encontrados, procedimento de Toda e Yamamoto, período 1980-2009, produtividade industrial

\begin{tabular}{|c|c|c|c|c|c|}
\hline \multicolumn{6}{|c|}{ Modelo $\mathbf{e}_{\mathbf{m}, \mathbf{i t}} \mathbf{g}_{m, \mathbf{i t}} \mathbf{g}_{\mathrm{s}, \mathbf{i}} \mathbf{g}_{\mathbf{k}, \mathbf{i t}}$} \\
\hline \multicolumn{3}{|c|}{ Variável dependente: $\mathbf{e}_{\mathbf{m}, \mathbf{i t}}$} & \multicolumn{3}{|c|}{ Variável dependente: $\mathbf{g}_{\mathbf{m}, \text { it }}$} \\
\hline Excluída & Qui quadrado & $\operatorname{Pr}$ & Excluída & Qui quadrado & $\operatorname{Pr}$ \\
\hline $\mathbf{g}_{\mathrm{m}, \mathrm{it}}$ & $4.131 *$ & 0 . & $\mathbf{e}_{\mathbf{m}, \text { it }}$ & 0.332 & 0 . \\
\hline $\mathbf{g}_{\mathrm{s}, \mathrm{it}}$ & 0.037 & 0 . & $\mathrm{g}_{\mathrm{s}, \mathrm{it}}$ & $3.407 * *$ & 0 . \\
\hline $\mathbf{g}_{\mathrm{k}, \mathrm{it}}$ & $2.874 * *$ & 0. & $\mathbf{g}_{\mathrm{k}, \mathrm{it}}$ & 0.145 & 0 . \\
\hline \multicolumn{3}{|c|}{ Variável dependente: $\mathbf{g}_{\mathbf{s}, \mathbf{i t}}$} & \multicolumn{3}{|c|}{ Variável dependente: $\mathbf{g}_{\mathbf{k}, \mathbf{i t}}$} \\
\hline Excluída & Qui quadrado & $\operatorname{Pr}$ & Excluída & Qui quadrado & $\operatorname{Pr}$ \\
\hline $\mathbf{e}_{\mathbf{m}, \mathrm{it}}$ & $17.774^{*}$ & 0. & $\mathbf{e}_{\mathbf{m}, \mathrm{it}}$ & 0.388 & 0. \\
\hline $\mathbf{g}_{\mathrm{m}, \mathrm{it}}$ & 1.969 & 0. & $\mathbf{g}_{\mathrm{m}, \mathrm{it}}$ & 0.324 & 0 . \\
\hline $\mathbf{g}_{\mathrm{k}, \mathrm{it}}$ & 0.008 & 0. & $\mathbf{g}_{\mathrm{s}, \mathrm{it}}$ & 2.522 & 0. \\
\hline $\operatorname{AIC}(3)$ & -30.09 & & & & \\
\hline BIC(1) & -28.03 & & & & \\
\hline Portmanteau & 25.93 & & & & \\
\hline
\end{tabular}

Fonte: Elaboração própria, * significativo ao nível de confiança de $95 \%$, ** significativo ao nível de confiança de $90 \%$

A Tabela 5 apresenta os resultados encontrados para o modelo que possui o valor adicionado per capita do setor industrial como variável explicada. Novamente, o critério de informação BIC indica que o modelo deve ser estimado com uma defasagem, adicionam-se duas defasagens exógenas para cumprir com as exigências do procedimento de Toda e Yamamoto. Os resultados obtidos mostram que apenas o crescimento do valor adicionado do setor de serviços intermediários causa Granger o crescimento do valor adicionado per capita do setor industrial.

Tabela 5 - Resultados encontrados, procedimento de Toda e Yamamoto, período 1980-2009, densidade industrial

\begin{tabular}{|c|c|c|c|c|c|}
\hline \multicolumn{6}{|c|}{ Modelo $\mathbf{D}_{\text {ind }} \mathbf{g}_{m, \mathbf{i t}} \mathbf{g}_{\mathbf{s}, \mathbf{i t}} \mathbf{g}_{\mathbf{k}, \mathbf{i t}}$} \\
\hline \multicolumn{3}{|c|}{ Variável dependente: $\mathbf{D}_{\text {ind }}$} & \multicolumn{3}{|c|}{ Variável dependente: $\mathbf{g}_{\mathbf{m}, \mathbf{i t}}$} \\
\hline Excluída & Qui quadrado & $\operatorname{Pr}$ & Excluída & Qui quadrado & $\operatorname{Pr}$ \\
\hline $\mathbf{g}_{\mathbf{m}, \mathrm{it}}$ & 1.191 & 0. & $\mathbf{D}_{\text {ind }}$ & 1.073 & 0 . \\
\hline $\mathbf{g}_{\mathrm{s}, \mathrm{it}}$ & $5.497 *$ & 0. & $\mathbf{g}_{s, i t}$ & $5.367 *$ & 0 . \\
\hline $\mathbf{g}_{\mathrm{k}, \mathrm{it}}$ & 0.142 & 0. & $\mathbf{g}_{\mathrm{k}, \mathrm{it}}$ & 0.234 & 0. \\
\hline \multicolumn{3}{|c|}{ Variável dependente: $\mathbf{g}_{\mathrm{s}, \mathbf{i t}}$} & \multicolumn{3}{|c|}{ Variável dependente: $\mathbf{g}_{\mathbf{k}, \mathbf{i t}}$} \\
\hline Excluída & Qui quadrado & $\operatorname{Pr}$ & Excluída & Qui quadrado & $\operatorname{Pr}$ \\
\hline$D_{\text {ind }}$ & 1.782 & 0. & $D_{\text {ind }}$ & 0.021 & 0 . \\
\hline $\mathbf{g}_{\mathbf{m}, \mathrm{it}}$ & 1.680 & 0 . & $\mathbf{g}_{\mathbf{m}, \mathrm{it}}$ & 0.001 & 0 . \\
\hline $\mathbf{g}_{\mathrm{k}, \mathrm{it}}$ & 0.125 & 0. & $\mathbf{g}_{\mathrm{s}, \mathrm{it}}$ & $3.285 * *$ & 0. \\
\hline $\operatorname{AIC}(3)$ & -35.00 & & & & \\
\hline BIC(1) & -33.17 & & & & \\
\hline Portmanteau & 43.05 & & & & \\
\hline
\end{tabular}

Fonte: Elaboração própria, * significativo ao nível de confiança de $95 \%$, ** significativo ao nível de confiança de $90 \%$

Em suma, os resultados obtidos evidenciam que o crescimento do valor adicionado do setor industrial gera estímulos fracos, os quais contribuem para o crescimento no valor adicionado do setor de serviços intermediários, mas não contribuem para o crescimento do PIB e do valor adicionado per capita do setor industrial. O setor industrial não está conseguindo se desenvolver plenamente, nem contribuir para o crescimento econômico nacional. Assim, na contramão da literatura kaldoriana, que percebe o setor industrial como motor do crescimento, no Brasil a indústria demonstra capacidade limitada de 
promover essa contribuição ao crescimento do PIB. ${ }^{13}$ Isto é, o processo de desindustrialização registrado pelo Brasil fez com que a indústria não conseguisse induzir um processo autodeterminado de crescimento econômico de longo prazo. Este setor permaneceu estagnado no período, perdendo suas propriedades virtuosas.

Por outro lado, o crescimento do setor de serviços exerce efeito positivo sobre o crescimento do PIB e o crescimento da indústria, sendo que o crescimento do PIB também resulta em crescimento do setor de serviços intermediários. Portanto, paradoxalmente, é o setor de serviços intermediários que apresentou um processo autossustentado de crescimento econômico e não o setor industrial, conforme proposto por Kaldor (1996). Estes resultados estão de acordo com as evidências encontradas por Di Meglio et al. (2015) e Dasgupta e Singh (2007), os quais mostram que o setor de serviços intermediários também consegue promover um processo de crescimento autossustentado do PIB, sendo dotado das propriedades atribuídas por Kaldor apenas para o setor industrial.

A Figura 1 formaliza a relação de causalidade existente entre o crescimento do PIB e do valor adicionado do setor industrial e do setor de serviços intermediários. Os pontos de interrogação são utilizados para enfatizar a necessidade de se identificar por que as relações de causalidade entre o crescimento do PIB e do setor industrial não emergem. As ligações entre indústria e serviços intermediários são apresentadas na forma tracejada para ressaltar que, apesar da existência de simbiose entre os setores, ela é fraca e compromete a dinâmica econômica nacional.

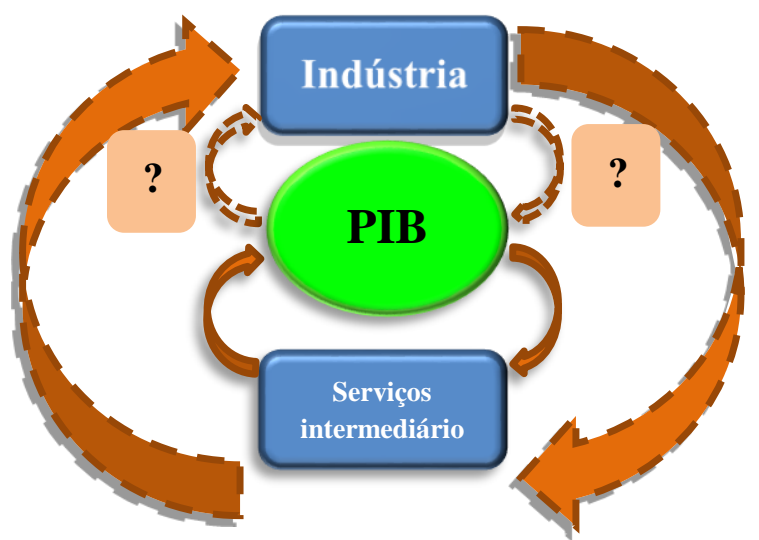

Figura1 - Relação de causalidade entre serviços, indústria e crescimento do PIB identificada pelo teste de Wald

Portanto, a questão a ser respondida é por que o setor industrial no longo prazo não vem contribuindo para o crescimento do PIB, bem como por que a simbiose entre indústria e serviços é reduzida no Brasil. A próxima seção procura desenvolver uma resposta a essa problemática, relacionando o desempenho industrial e do setor de serviços internacionalmente, e a estrutura industrial e de serviços brasileira, para melhor entender a estagnação nacional no longo prazo.

\section{5) Inércia estrutural e desempenho internacional comparado: uma explicação para a reduzida simbiose entre indústria e serviços intermediários}

Conforme demonstrado na seção 2, nas últimas décadas ocorreu um processo intenso de transformação produtiva e tecnológica, sobretudo nas economias desenvolvidas. Tal fenômeno evidenciou uma nova relação dinâmica entre os setores indústria e serviços intermediários, no qual este último também passou a contribuir de maneira significativa para o surgimento de inovações e ganhos de produtividade no setor industrial. Procuramos mostrar nesta seção que essa nova relação de simbiose entre indústria e serviços é reduzida na economia brasileira no período em tela.

O teste de causalidade identificou que existe simbiose entre indústria e serviços no Brasil, porém argumentamos que essa relação é fraca em razão do reduzido crescimento econômico nacional no

\footnotetext{
${ }^{13}$ É importante enfatizar que estes resultados se referem a crescimento de longo prazo, dado que se utilizou a média de seis anos para se filtrar a relação de curto prazo. Eles nada dizem sobre o ciclo econômico em si.
} 
período. Procuramos demonstrar a seguir que a relação simbiótica entre os setores é enfraquecida por duas razões: 1) De forma direta, porque a indústria não contribui para o PIB em razão de seu baixo desempenho relativo internacional e pela sua inércia estrutural. 2) Indiretamente, porque os serviços, apesar de contribuem para o crescimento do PIB também apresentam reduzido desempenho relativo internacional e, além disso, prejudicam o desempenho do setor industrial via oferta de precários serviços de custos e de valor, enfraquecendo a simbiose promotora do crescimento autossustentado.

Afim de melhor compreender o desempenho dos setores indústria e serviços intermediários no longo prazo, e ao mesmo tempo relativizar seus desempenhos com o de outras economias, o Gráfico 1 consolida comparações através dos Indicadores (DRI) de Desindustrialização Relativa Internacional e de Deservicilização Relativa Internacional. ${ }^{14}$ Conforme se observa, o Brasil apresenta desindustrialização e deservicilização relativa contra todos os casos considerados, inclusive contra países considerados com menor dinamismo econômico, como a África Subsaariana. Os Vários DRIs indicam que os setores indústria e de serviços intermediários do Brasil não obtiveram crescimento superior a nenhuma das regiões/países considerados.

Gráfico 1- Evolução do indicador de DRI - indústria e serviços intermediários, período 1980-2009.
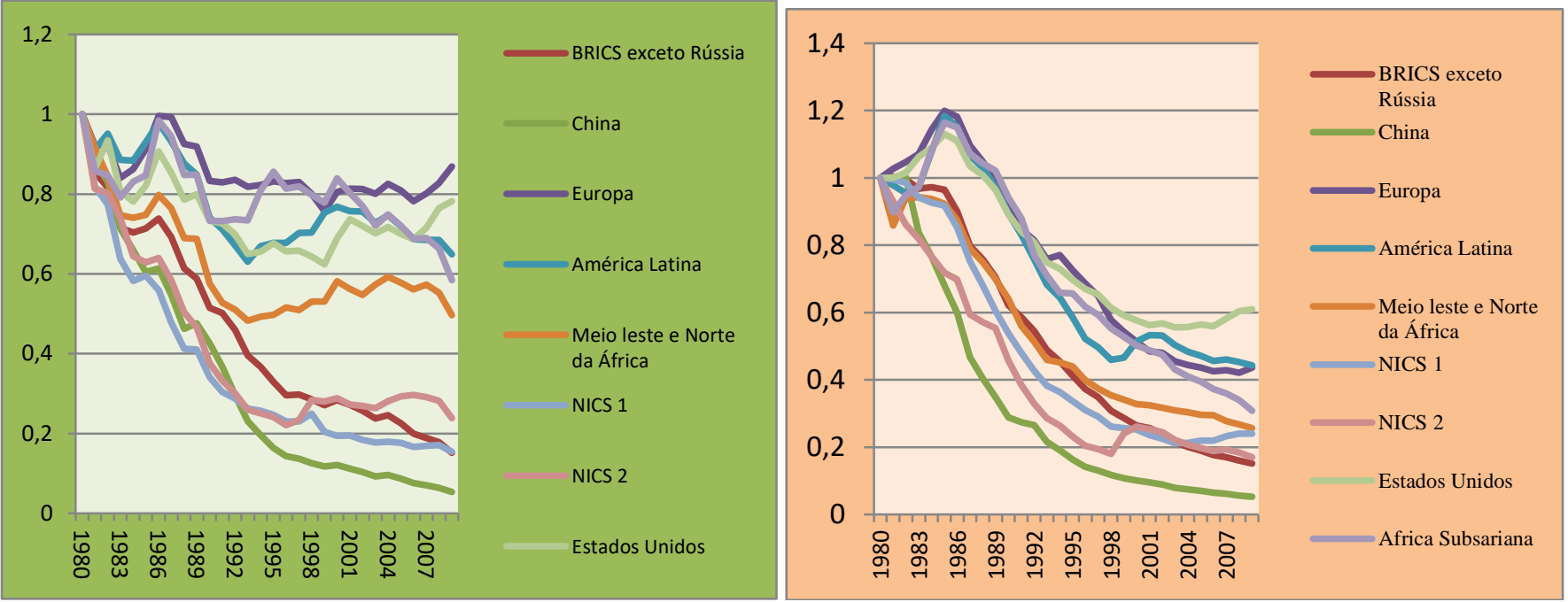

Fonte: Elaboração própria a partir dos dados disponibilizados pelo Groningen GrowthandDevelopment Centre.

As comparações internacionais relevam que, a partir da década de 1980, o Brasil não conseguiu acompanhar o crescimento da indústria e, principalmente, dos serviços intermediários apresentados pela quase totalidade dos países e grupos de países da economia global. Na contramão da literatura e das evidências empíricas que advogam pela nova relação de sinergia entre serviços intermediários e indústria, a partir dos anos 1980, a economia brasileira revela uma relativa estagnação nesses setores-chaves para a promoção do desenvolvimento econômico e um processo de crescente desindustrialização que emerge a partir desta mesma década.

\footnotetext{
${ }^{14} \mathrm{O}$ indicador é construído a partir do índice do Valor da Produção Industrial (IVI), que em última instância trata-se de um número-índice que busca mostrar a variação relativa do valor da produção industrial (VPI) entre um período $t$ e um período $t+n$. o IVI pode ser expresso pela seguinte fórmula:

$I V I_{t, t+n}=\left(\frac{V P I_{t+n}}{V P I_{t}}\right) * 100$. Arend (2014) expõe que o DRI é construído a partir do IVI, e pode ser expresso por: $D R I_{t p a i ́ s}=$ $I V I_{\text {tpaís }} / I V I_{\text {tpaísouregiãoreferência. }}$ DRI $>1$ = crescimento relativo do VPI do país maior. Ou seja, em termos relativos, o país está se industrializando a uma taxa mais elevada que o país/região referência. $D R I<1=$ crescimento relativo do VPI do país menor. Quer dizer, em termos relativos, o país está se desindustrializando em relação ao país/região de referência. Assim, o DRI procura mostrar o desempenho industrial relativo de determinado país em relação ao país/região referência. Um valor menor que 1 , indica que o país está apresentando uma taxa de crescimento do produto manufatureiro menor do que o país de referência, o que pode caracterizar o que denominamos de um processo de desindustrialização internacional relativa. A mesma análise para o setor industrial foi aplicada ao setor de serviços intermediários.
} 
Em relação ao reduzido desempenho industrial, cabe destacar que, com o esgotamento das possibilidades de inversão nos complexos metal-mecânico-químico, nos anos 1970, os países desenvolvidos buscaram se reestruturar tecnológica e produtivamente. Segundo Laplane (1992), a partir dos anos 1980, o eixo dinâmico da atividade industrial nestes países migrou do setor Automobilístico para as novas tecnologias de comunicação. Essa transformação tecnológica e produtiva ficou consagrada na literatura neoschumpeteriana pela transição de paradigma tecnoeconômico (PEREZ, 2004).

Nessas tecnologias a produção de bens de consumo duráveis, com destaque para a cadeia produtiva de eletroeletrônicos, componentes (como semicondutores, circuitos integrados e transistores) e produtos eletroeletrônicos finais, apresentou considerável concentração nos países asiáticos, enquanto a produção de softwares foi liderada por empresas localizadas no "Vale do Silício", nos Estados Unidos (SIQUEIRA, 2007). As novas tecnologias de comunicação possibilitaram a retomada do desenvolvimento econômico nos países centrais, mas a fabricação destes produtos não se propagou para as economias periféricas. Isso porque elas demandam acentuada transferência de conhecimento técnico e fazem uso mais intensivo de mão-de-obra com alto conhecimento e qualificação (AREND, 2009).

A análise da evolução da estrutura industrial no período 1996-2010, discriminada de acordo com a especificidade tecnológica, (Gráfico 3) mostra que o Brasil permaneceu à margem do movimento de reestruturação produtiva observado nos países capitalistas. O grupo das commodities industriais foi o que deteve a maior participação na estrutura industrial brasileira (33\%) no ano de 2010, além de ter apresentado tendência de ganhos de participação desde o ano 2002. Na segunda posição encontra-se a indústria tradicional intensiva em mão-de-obra (30\%). Juntamente com o grupo das commodities agrícolas, estes três grupos industriais correspondiam, em 2010, a aproximadamente $74 \%$ do parque industrial brasileiro, indicando elevada especialização produtiva do Brasil em setores intensivos em mãode-obra e em recursos naturais. $\mathrm{O}$ grupo que corresponde aos setores intensivos em tecnologia típicos do paradigma fordista (metal-mecânico-químico) chega ao ano de 2010 com participação de 23\%, também com tendência a elevação desde 2007. Já o grupo que corresponde aos setores industriais intensivos em tecnologia do paradigma microeletrônico (novas tecnologias de comunicação) registrou participação de apenas 2,4\% na estrutura produtiva no ano de 2010, além de apresentar tendência de queda na participação.

Gráfico 3 - A Evolução da estrutura industrial do Brasil (VTI) no período 1996-2010, segundo grupos industriais de acordo com sua especificidade tecnológica. ${ }^{15} \mathrm{~B}$ ) Participação percentual na indústria de transformação dos setores de material eletrônico e de aparelhos e equipamentos de comunicações nos anos de 2000 e 2009

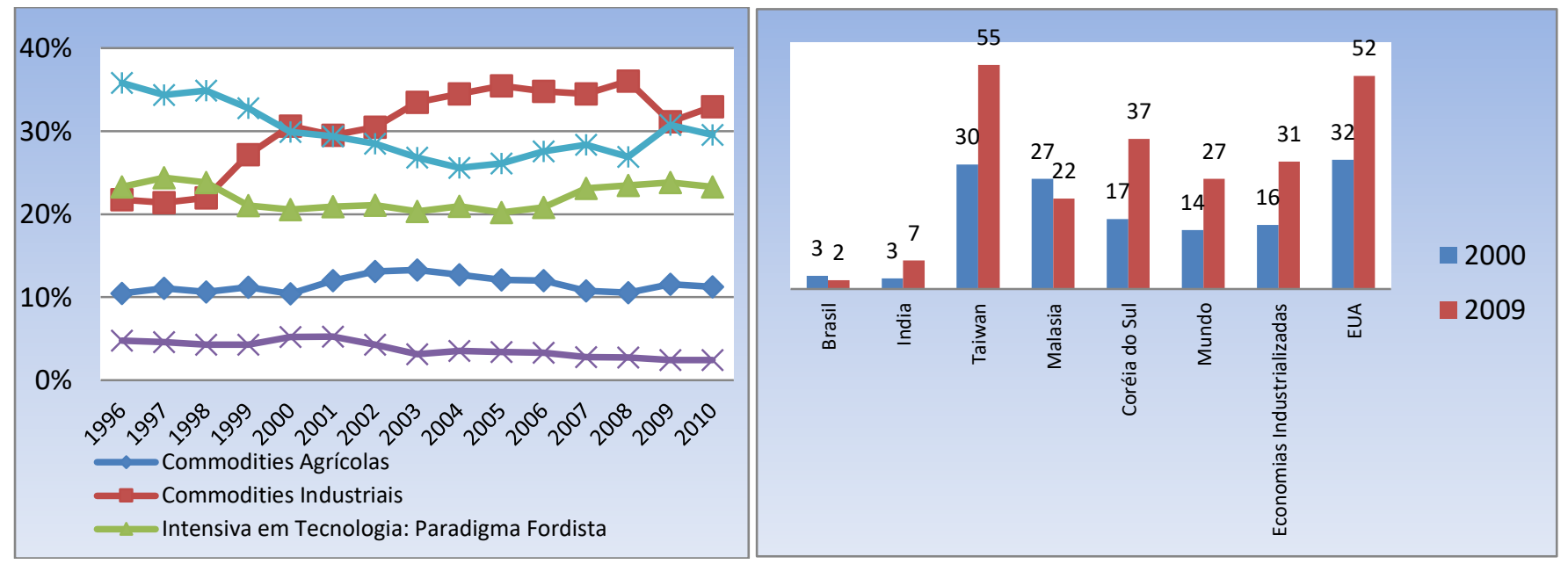

Fonte: a) Elaborado pelo autor. b) Elaborado pelo autor a partir de dados da UNIDO

\footnotetext{
15 A metodologia utilizada para a classificação industrial deriva da tipologia desenvolvida pelo GIC-IE/UFRJ (Grupo de Indústria e Competitividade/Instituto de Economia da Universidade Federal do Rio de Janeiro) para análise da estrutura produtiva brasileira. A diferença neste estudo foi a de incorporar o complexo do petróleo e dividir o grupo intensivo em tecnologia em dois: fordista e microeletrônico.
} 
Estas informações mostram que a estrutura industrial do Brasil é composta, predominantemente, por commodities (agrícolas e industriais) e setores fordistas. A comparação com outros países revela a baixa participação relativa das novas tecnologias de comunicação na indústria brasileira. $\mathrm{O}$ país pouco internalizou estas tecnologias em sua estrutura produtiva. ${ }^{16}$

Dessa forma, no Brasil, os setores industriais intensivos em tecnologia são correspondentes ao paradigma fordista, em declínio nas principais economias avançadas desde a década de 1980. Conforme demostrado por Castellacci (2008) as firmas caracteristicas do paradigma fordista fomentam o crescimento de fornecedores especializados (por exemplo, produtores de instrumentos de precisão) e de serviços de infraestrutura (em especial, serviços de infraestrutura física, como transporte). Contudo, com a difusão das novas tecnologias de comunicação, as maiores oportunidades tecnológicas podem ser encontradas em outros setores. Os produtores de software e hardware podem ser vistos como os fabricantes de produção em massa de alta oportunidade da atualidade. Em sua trajetória dinâmica, esses setores demandam provedores avançados de conhecimento (como software e consultoria técnica) e de serviços de infraestrutura de rede (por exemplo, telecomunicações). É o intercâmbio de conhecimentos avançados, bens e serviços entre esses setores de fabricação e serviços de alta oportunidade que são responsáveis pela maior parte do potencial de crescimento da era atual. O fato do Brasil não ter entrado integralmente neste novo paradigma explica o processo de desindustrialização observado em território nacional. Dado que o setor industrial é responsável por demandar soluções tecnológicas oriundas do setor de serviços intermediários, isto também explica o processo de deservicilização relativa internacional, registrado pelo Brasil. Isto é, dada a emergência das novas tecnologias de comunicação, o setor de serviços cresce e puxa o crescimento do PIB. Contudo, o baixo dinamismo do setor industrial compromete o crescimento do setor de serviços intermediários. Como resultado, este setor não consegue exercer todo o seu potencial, o que explica o baixo desempenho registrado pela economia brasileira no período 1970-2009.

Estes resultados são corroborados pela teoria da complexidade econômica. Conforme demonstrado por Hidalgo et al (2007), Hidalgo e Hausmann (2009) e Hausmann e Hidalgo (2011), os países em desenvolvimento se encontram na periferia do espaço-produto, fabricando produtos que possuem poucas conexões. Como consequência, estes países possuem maior dificuldade em diversificar a sua estrutura produtiva e migrar para a fabricação de produtos que demandam mais conhecimento. Seguindo Nübler (2014) se defende que a realização de políticas de mudança estrutural, que estimulem as firmas a migrarem para novas comunidades de conhecimentos, maiores e mais intensivas em serviços intermediários poderia contribuir para o fortalecimento do setor industrial.

Os resultados obtidos para os testes de causalidade parecem jogar toda a culpa do faling behind internacional brasileiro no setor industrial, dado que este é o setor que não contribui para o crescimento econômico de longo prazo no período analisado. Todavia, grande parte da estagnação industrial brasileira também decorre de problemas apresentados pelo setor de serviços. O comportamento deste setor no período analisado apresenta anomalia quando comparado ao padrão internacional. Conforme destacado por Oulton (2000), a partir da década de 1970 os países observaram o aumento na participação do setor de serviços intermediários no valor adicionado, em detrimento dos serviços finais. Assim, os serviços que registraram crescimento foram os utilizados pela indústria e não os serviços finais, sendo inválida a “doença de custos" proposta por Baumol (1967). Porém, quando se analisam os dados brasileiros o que se observa é justamente o contrário, a participação dos serviços finais aumentou consideravelmente a partir de 1985 (ARBACHE, 2015b). Isto é, a "doença de custos" continua válida para o Brasil. As atividades que cresceram em território nacional foram atividades de serviços, porém serviços de pior qualidade e que não possuem simbiose com a indústria, que geram menor nível de renda e que menos contribuem para o crescimento econômico. Segundo Arbache (2012), o aumento na participação destas atividades de

\footnotetext{
16 Também ratificando as informações apresentadas acima, Carneiro (2008) constatou que, entre os anos 1993 e 2006 , ocorreu uma grande modificação na estrutura da indústria dos países desenvolvidos em direção a uma ampliação significativa da participação da indústria de material eletrônico e de comunicação. Os países em desenvolvimento, em especial os asiáticos, acompanham a mudança em direção à preeminência desse setor e, também, diferenciam a sua indústria nessa direção. Na indústria brasileira, ao contrário, o houve um movimento anacrônico em direção ao setor emblemático do paradigma microeletrônico.
} 
serviços ajuda a explicar o recuo das taxas de crescimento da produtividade e do PIB no período pós 1990.

Conforme evidenciado pelas estimações realizadas, e pelos indicadores de deservicilização, desindustrialização relativa e evolução da estrutura produtiva, existem duas forças que atuam sobre o setor de serviços intermediários, cada uma em determinado sentido: 1) a emergência das novas tecnologias de comunicação estimula o crescimento dos serviços intermediários, enquanto que 2) a desindustrialização induz um processo de acomodação das forças produtivas locais, resultando em mudança estrutural redutora de produtividade (AREND et Al., 2016) e deservicilização. Ela estimula o aumento na participação dos serviços finais em detrimento dos serviços intermediários. Como resultado, dado o aumento na importância relativa dos serviços intermediários para a inserção dos países nas cadeias globais de valor (OCDE/OMC, 2013; NORDÅS, 2008; NORDÅS e KIM 2013), o baixo dinamismo deste setor em território nacional contribui para a perda de competitividade internacional e para a continuidade do processo de desindustrialização nacional. Este mesmo setor sofre as consequências deste processo, formando-se um ciclo vicioso e prejudicial ao crescimento da economia brasileira em que o baixo dinamismo do setor de serviços resulta em crescente exclusão das cadeias globais de valor, o que resulta em desindustrialização induzindo deservicilização, reiniciando-se o ciclo.

Os serviços nacionais restringem de dois modos diferentes a competitividade do setor industrial. Por um lado, a sua baixa produtividade e competitividade internacional infla a estrutura de custos industriais, fazendo com que setores industriais que fabricam produtos commoditizados não sejam competitivos. Por outro lado, os serviços que deveriam contribuir para a agregação de valor aos produtos industriais ainda são incipientes. Dado que os setores industriais que fabricam produtos mais sofisticados dependem desta relação de simbiose, eles não conseguem se desenvolver plenamente. Como resultado, a indústria nacional não consegue competir no mercado, sendo incapaz de contribuir para o crescimento do PIB, observando retração em sua participação no valor adicionado. Analisaremos cada um destes pontos na sequência.

Arbache (2017) argumenta que a partir de 1980 a produtividade relativa internacional dos serviços brasileiros recuou, enquanto que a produtividade industrial voltou a crescer na década de 1990. Ele aponta para a falta de dinamismo no setor de serviços como possível fonte da estagnação industrial. Com efeito, a produtividade do trabalho no setor de serviços é a que apresenta maior defasagem em comparação com outros países. Esta equivale a apenas $19 \%$ da produtividade dos Estados Unidos, enquanto que a produtividade industrial brasileira equivale a $32 \%$ e a produtividade da indústria extrativa a $77 \%$ da produtividade americana.

Para Arbache (2017, 2015a), quatro fatores contribuem para a baixa eficiência e a baixa adoção de novas tecnologias e melhores práticas entre as firmas brasileiras de serviços. O primeiro se refere ao tamanho diminuto das firmas nacionais, que possuem valor agregado médio de apenas $\mathrm{R} \$ 5.600,00$ por mês e 5,2 trabalhadores por firma. O segundo fator é o salário líquido (excluindo impostos sobre a folha de pagamento) que a partir de 2000 aumentou mais rapidamente do que o valor agregado por trabalhador e mais do que na indústria. $O$ terceiro fator é a rotatividade de empregos, cerca de quatro vezes maior do que no resto da economia, o que desencoraja o investimento em capital humano, contribuindo para a sua baixa produtividade. E, o quarto fator é o baixo acesso das firmas do setor de serviços ao sistema financeiro, o que dificulta a aquisição de novas tecnologias. ${ }^{17}$

Além destes fatores existem diversos outros que diminuem a concorrência, garantem reservas de mercados para empresas nacionais e restringem a produtividade do setor de serviços. O setor de serviços é o que mais paga impostos, $24 \%$ de sua receita total contra $19,4 \%$ da produção e consumo de bens e serviços como um todo. Este setor também é excessivamente regulamentado no país. O índice STRI (Services Trade Restrictiveness Index), disponibilizado pela OCDE, mostra que as atividades de serviços do Brasil possuem regulamentação superior a média geral, exceto em distribuição e serviços legais. A limitação à movimentação de pessoas também contribui para a baixa competitividade nacional,

\footnotetext{
${ }^{17}$ Os bancos brasileiros cobram altos diferenciais de juros entre as taxas de empréstimos e a remuneração dos depósitos, sendo que estes spreads cresceram no período recentemente. Parte desse fenômeno pode ser atribuída à pressões inflacionárias e à volatilidade macroeconômica, mas o quadro regulatório e a falta de pressão competitiva sobre os principais bancos também desempenham um papel substancial (ARBACHE, 2017).
} 
trabalhadores estrangeiros só podem ser contratados se não existirem trabalhadores nacionais que possam ocupar o cargo. Além disto, gestores de sociedades por ações devem residir no Brasil e $2 / 3$ dos funcionários destas empresas devem ter nacionalidade brasileira. Isto diminui a concorrência e cria um ambiente pouco favorável a maior qualificação dos trabalhadores. As barreiras ao comércio internacional e a regulamentação excessiva são outros entraves ao aumento da produtividade do setor de serviços. ${ }^{18}$

Além da presença de barreiras que criam um ambiente de baixa pressão e concorrência no setor de serviços, outras explicações para a baixa produtividade deste setor são: os investimentos fracos em infraestrutura; as mudanças nos preços relativos em favor dos serviços devido ao aumento das importações de bens manufaturados; sobrevalorização cambial e a aceleração do salário mínimo real, observados a partir dos anos 2000. Efeito de todos estes fatores, o país se encontra mal posicionado em diversas classificações internacionais: infraestrutura; em outros serviços públicos: energia para fins industriais, o preço do gás para fins industriais, o custo médio de acesso à internet, e o custo médio dos serviços de contêineres marítimos. Todos estes serviços são demasiadamente caros em território nacional e comprometem o crescimento e a produtividade da indústria. Como resultado, o setor de serviços infla a estrutura de custos do setor industrial (ARBACHE, 2017).

A Figura 2 discrimina estes dois grupos de serviços, destacando o modo como eles influenciam no dinamismo do setor industrial. Acima de cada seta se encontra a função de cada grupo de serviços e abaixo o custo/oportunidade que eles representam para a indústria brasileira.

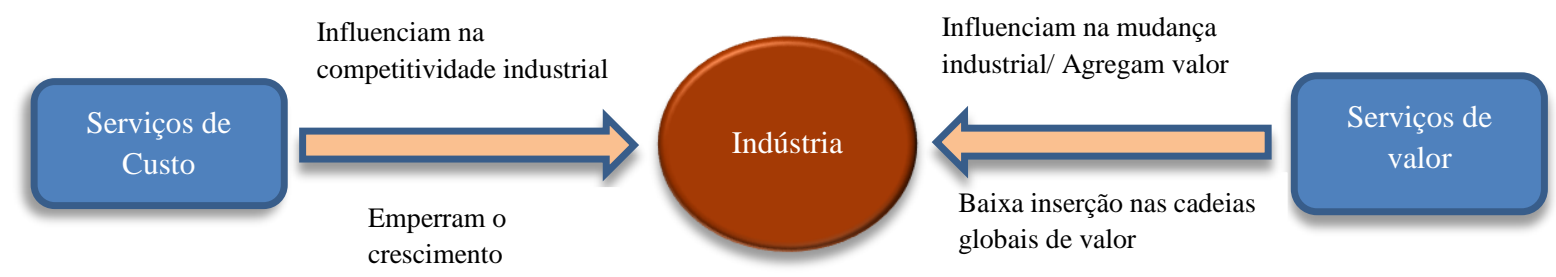

Figura 2 - As contribuições dos diferentes grupos de serviços para a competitividade industrial Fonte: Elaboração própria

Arbache (2017) mostra que os serviços de custos não contribuem para o aumento da produtividade industrial, mas eles são necessários para levar a cabo a produção e para que as empresas sejam competitivas $^{19}$. Deste modo, o preço elevado destes serviços compromete a competitividade industrial, sendo a redução do preço destes serviços elemento vital para que a indústria volte a ser competitiva. A Figura 1 mostra que estes serviços, atualmente, reduzem a competitividade do setor industrial, emperrando o seu crescimento.

A falta de causalidade entre crescimento do setor industrial e o crescimento do PIB, apresentado pelo modelo estimado através do procedimento de Toda e Yamamoto, pode ser explicada, em parte, pela baixa competitividade destes serviços. Estes, ao inflar os custos das empresas, diminuem a sua

\footnotetext{
${ }_{18}$ As importações de serviços específicos estão sujeitas ao pagamento de $10 \%$ de CIDE (Contribuição de Intervenção no Domínio Econômico). Este tributo onera principalmente serviços relacionados às novas tecnologias, que são particularmente importantes para a atualização tecnológica de empresas industriais. A lei de aquisição é outro mecanismo que favorece empresas nacionais em detrimento de fornecedores estrangeiros de serviços e que desestimula a concorrência e o aumento na eficiência dos serviços prestados por empresas nacionais. Ela permite a definição, por decreto, de margens de preferência de até $25 \%$ do preço de bens e serviços específicos produzidos no Brasil (ARBACHE, 2017).
}

\footnotetext{
${ }^{19}$ Arbache (2014) classifica os serviços em dois grupos.1) Os serviços de custos e refere a funções que afetam os custos de produção, incluindo logística e transporte, serviços de infraestrutura geral, serviços de armazenamento, reparação e manutenção, serviços terceirizados em geral, serviços básicos de TI, crédito e serviços financeiros, viagens, alojamento, Comida e restauração, ou distribuição. 2) Os serviços de valor se referem a funções que agregam valor, diferenciam e personalizam produtos, elevando o seu valor de mercado. Estes serviços incluem projetos de P\&D, design, engenharia e arquitetura, serviços de consultoria, software, serviços técnicos especializados, serviços de TI de alta qualidade, branding, publicidade e marketing.
} 
competitividade e fazem com que o setor industrial permaneça estagnado e não contribua para o crescimento do PIB.

Dado que os serviços de custos não elevam a produtividade industrial, a redução dos preços e o aumento na qualidade destes serviços dificilmente serão capazes de fazer a indústria aumentar a sua inserção nas cadeias globais de valor e voltar a ser o motor de dinamismo da economia. Esta função fica reservada para os serviços de valor. Conforme demonstrado por Shih (1992), estes serviços contribuem para o aumento da produtividade industrial. O seu desenvolvimento pode fazer com que a indústria nacional se integre cada vez mais nas cadeias globais de valor, voltando a contribuir para o crescimento econômico. Assim, dada a literatura que mostra que serviços de qualidade, localizados nas pontas da curva sorridente, são cada vez mais importantes para que os países consigam aumentar a sua participação nas cadeias globais de valor (OECD/OMC, 2012), o desenvolvimento destes serviços em território nacional pode reativar os mecanismos propostos por Kaldor e que atualmente não estão operando.

\section{CONSIDERAÇÕES FINAIS}

O procedimento proposto por Toda e Yamamoto foi utilizado para identificar se o setor de serviços intermediários contribui para o crescimento econômico, o aumento do valor adicionado per capita da indústria e o crescimento da produtividade industrial do Brasil. Os dados utilizados para as estimações foram obtidos no site do Gronigen Growth and Development Center para o período 19702009, sendo obtida a média decenal para eliminar a relação de curto prazo (ciclo econômico) entre as variáveis.

A literatura de serviços mostra que a fabricação de produtos industriais mais sofisticados demanda maior volume de conhecimentos. Os serviços intermediários possuem como principal função o fornecimento de conhecimento tecnológico à indústria. Assim, este setor contribui para o crescimento do setor industrial e para o surgimento de inovações e o aumento de sua produtividade. A sua presença é condição cada vez mais necessária para que os países consigam diversificar sua produção para produtos industriais mais sofisticados.

A comparação com outras regiões/países revela que, no período 1980-2009, o Brasil passou por um processo de desindustrialização e deservicilização relativa. Ele não conseguiu obter crescimento superior a nenhuma das regiões/países considerados. Estes dados revelam o quadro dramático de mudança estrutural regressiva enfrentado pelo país.

O procedimento de Toda e Yamamoto apontou para a existência de uma relação de simbiose entre o setor industrial e o setor de serviços intermediários. O setor de serviços intermediários contribui para o crescimento do PIB e do valor adicionado do setor industrial. Porém, o crescimento no valor adicionado do setor industrial resulta em crescimento dos serviços intermediários, mas não resulta em crescimento do PIB. Estes resultados representam um paradoxo, eles indicam que o setor industrial não conseguiu promover crescimento autossustentado da economia brasileira no período 1980-2009. Por outro lado, o crescimento do setor de serviços intermediários resultou em crescimento autossustentado do PIB, apresentando, ao contrário do setor industrial, as propriedades promotoras do crescimento econômico atribuídas originalmente por Kaldor.

Os resultados encontrados também mostraram que o crescimento do setor de serviços intermediários não se deve apenas ao crescimento do PIB. Dado que este setor fornece soluções tecnológicas para o setor industrial, parte considerável de seu crescimento depende do crescimento industrial. Assim, argumenta-se que o quadro de desindustrialização observado pela economia brasileira pode estar comprometendo o crescimento dos serviços intermediários e, indiretamente, do PIB. Ademais, isto pode explicar o quadro de deservicilização e desindustrialização relativa internacional, observado pela economia brasileira no período 1980-2009.

$\mathrm{O}$ fato de o setor industrial não contribuir para o crescimento do PIB pode, facilmente, levar a conclusão de que o problema brasileiro se encontra na indústria e não no setor de serviços intermediários. Contudo, a visão aqui defendida é que o problema é mais complexo, o setor de serviços intermediários também apresenta limitações. A importância deste setor se elevou nas últimas décadas, influenciando na 
capacidade dos países em ingressar nas cadeias globais de valor e na capacidade do país em realizar um processo de mudança estrutural para setores mais avançados tecnologicamente. Assim, o processo de desindustrialização nacional decorre de limitações apresentadas pelo setor industrial, do fato do país não ter conseguido ingressar com êxito no novo paradigma tecnológico e da inexistência de serviços adequados. Com o aumento da importância relativa destes serviços frente ao novo paradigma tecnoeconômico e da constatação de seu crescimento restrito em território nacional, a partir da década de 1980 o país perdeu competitividade, se desindustrializando e deservicilizando em termos internacionais.

\section{REFERÊNCIAS}

AREND, Marcelo. A industrialização do Brasil ante a nova divisão internacional do trabalho. In: André Bojikian Calixtre; André Martins Biancarelli; Marcos Antônio Macedo Cintra. (Org.). Presente e futuro do desenvolvimento brasileiro. 1ed. Brasilia: Ipea, 2014, v. , p. 375-422.

AREND, Marcelo; SINGH, G. L.; BICHARRA, J. S. MUDANÇA ESTRUTURAL REDUTORA DA PRODUTIVIDADE: O FALLING BEHIND BRASILEIRO. In: 44 Encontro Nacional de Economia, 2016, Foz do Iguaçu, 2016.

AREND, M. 50 anos de industrialização do Brasil (1955-2005): uma análise evolucionaria. (tese de doutorado). PPGE/UFRGS, Porto Alegre, 2009.

ARBACHE, Jorge. The Contribution of Services to Manufacturing Competitiveness in Brazil, in A. Hualde, R. Hernandez, N. Mulder and P. Sauvé (eds.), Innovation and Internationalization in Latin America Services, ECLAC, Santiago, 2016.

ARBACHE, Jorge. Produtividade no Setor de Serviços, in F. De Negri and L.R. Cavalcante (eds), Produtividade no Brasil: Desempenho e Determinantes. Volume II, Instituto de Pesquisa Econômica e Aplicada, Brasília, 2015a.

ARBACHE, Jorge. Por que Serviços? 2015b. Disponível em:

http://tracegp.sesi.org.br/bitstream/uniepro/77/1/ARTIGO_Servi\%c3\%a7os\%20e\%20ind\%c3\%bastria_Ar bache.pdf, acesso em: 03 de jul. 2017.

ARBACHE, Jorge. Serviços e Competitividade Industrial no Brasil, Confederação Nacional da Indústria, Brasília, 2014.

ARBACHE, Jorge. Is Brazilian manufacturing losing its drive? Brasília: UnB, 2012. Mimeo grafado. Disponível em: <http://papers.ssrn.com/sol3/papers.cfm?abstract_id=2150684>.

AMITI, M.; WEI, S. Fear of service outsourcing: is it justified? Economic policy, v. 20, n. 42, p. 308347, 2005.

BARKER, T.; FORSSELL, O Manufacturing, Services and Structural Change, 1979-1984. In: Structural change in the UK economy. Cambridge University Press, 1992.

BERLINGIERI, G. Essays on international trade and firm organization. 2013. Tese (PhD) Department of Economics of the London School of Economics. 2013.

BHAGWATI, J.N. Splintering and disembodiment of services and developing nations.The World Economy, 7, 133-143, 1984.

BOZDOGAN, Hamparsum. Model selection and Akaike's information criterion (AIC): The general theory and its analytical extensions. Psychometrika, v. 52, n. 3, p. 345-370, 1987.

BRYSON, J. R.; DANIELS, P. W.; WARF, B. Service Worlds: People, Organizations. Technology, 2004.

CAINELlI, G.; EVANGELISTA, R.; SAVONA, Maria. Innovation and economic performance in services: a firm-level analysis. Cambridge Journal of Economics, v. 30, n. 3, p. 435-458, 2006.

CARTER, A. P. Structural change in the american economy. Harvard University Press, 1970.

CARNEIRO, R. Impasses do desenvolvimento brasileiro: a questão produtiva. Campinas: IE/UNICAMP, 2008. 56 p. (Texto para discussão, n. 153).

CASTELLACCI, F. Technological paradigms, regimes and trajectories: Manufacturing and service industries in a new taxonomy of sectoral patterns of innovation. Research Policy, v. 37, n. 6, p. 978-994, 2008. 
CUADRADO-ROURA, J. R.; MAROTO-SANCHEZ, A. Regional productivity growth in European countries. The role of services. In: ERSA conference papers. European Regional Science Association, 2011.

CZARNITZKI, D.; RAMMER, C.; SPIELKAMP, A. Interaktionz wischen Wissenschaft und Wirtschaft in Deutschland: ErgebnisseeinerUmfragebeiHochschulenundöffentlichenForschungseinrichtungen. ZEW-Dokumentation, 2000.

DASGUPTA, S.; SINGH, A. Manufacturing, services and premature deindustrialization in developing countries: A Kaldorian analysis. In: Advancing Development. Palgrave Macmillan UK, p. 435-454, 2007.

DE NEGRI, Fernanda; CAVAlCANTE, Luiz Ricardo. Produtividade no Brasil: desempenho e determinantes. Brasília: ABDI, 2014.

DI CAGNO, D., MELICIANI, V. Do inter-sectoral flows of services matter for productivity growth? An input/output analysis of OCDE countries.Economics of Innovation and New Technology, v. 14, n. 3, p. 149-171, 2005.

DI MEGLIO, G.et al Services in Developing Economies: A New Chance for Catching-Up? 2015. SWPS 2015-32. Available at SSRN: https://ssrn.com/abstract $=2744647$ or http://dx.doi.org/10.2139/ssrn.2744647

FEENSTRA, Robert C. et al. The Next Generation of the Penn World Table. American Economic Review, 105(10), 3150-3182, 2015.

FRANCOIS, J. e WOERZ, J. Producer services, manufacturing linkages, and trade. Journal of Industry, Competition and Trade, v. 8, n. 3-4, p. 199-229. Out 2008.

FRANKE, R.; KALMBACH, P. Structural change in the manufacturing sector and its impact on business-related services: an input-output study for Germany. Structural Change and Economic Dynamics, v. 16, n. 4, p. 467-488, 2005.

FREUND, C., WEINHOLD, D. TIC diffusion and its impact in OECD countries. STI Review, v. 20, p. 13-36, 2002.

GALLOUJ, F.; WEINSTEIN, O. Innovation in services. Research policy, v. 26, n. 4, p. 537-556, 1997.

GEREFFI, G.; FREDERICK, S. The global apparel value chain, trade and the crisis: challenges and opportunities for developing countries. World Bank Policy Research Working Paper Series, p. 157208, 2010.

GUERRIERI, P.; MELICIANI, V. Technology and international competitiveness: the interdependence between manufacturing and producer services. Structural Change and Economic Dynamics, v. 16, n. 4, p. 489-502, 2005.

HAUSMANN, R.; HIDALGO, C. A. The network structure of economic output.Journal of Economic Growth, v. 16, n. 4, p. 309-342, 2011.

HIDALGO, C. A. et al. The product space conditions the development of nations. Science, v. $317, \mathrm{n}$. 5837, p. 482-487, 2007.

HIDALGO, C. A.; HAUSMANN, R. The building blocks of economic complexity. proceedings of the national academy of sciences, v. 106, n. 26, p. 10570-10575, 2009.

HERTOG, Pim D. Knowledge-intensive business services as co-producers of innovation. International Journal of Innovation Management, v. 4, n. 04, p. 491-528, 2000.

HIRSCHMAN, A. O. The strategy of economic growth. Yale. New Haven, 1958.

HOEKMAN, B. Protection and trade in services. World Bank, Policy Research Working Paper,n. 1747, 1997.

IMBS, J. e WACZIARG, R. Stages of diversification. American Economic Review, v. 93; n. 1, 2003.

JOHNSON, S., OSTRY J. D., SUBRAMANIAN A. The Prospects for Sustained Growth in Africa: Benchmarking the Constraints. IMF Staff Papers, v. 57, 2010.

JORGENSON, D. W., MUN S. H., e KEVIN J. S. A Retrospective Look at the U.S. Productivity Growth Resurgence. Journal of Economic Perspectives, v. 22, n. 1 3-24, 2008.

JORGENSON, D. W.; TIMMER, M. P. Structural Change in Advanced Nations: A New Set of Stylised Facts. The Scandinavian Journal of Economics, v. 113, n. 1, p. 1-29, 2011. 
KALDOR, N. Causes of the slow rate of economic growth of the United Kingdom: an inaugural lecture. Cambridge University Press, 1966.

KENDRICK, John W. Measurement of output and productivity in the service sector. Managing the service economy, prospects and problems, p. 111-133, 1985.

KUZNETS, S. Quantitative aspects of the economic growth of nations, Part II. Economic Development and Cultural Change, v. 5, n. 4, p. 1-111, 1957.

KUZNETS, S. Economic growth and income inequality. American Economic Review, v. 45, p. 1-28, 1955.

KUZNETS, S. Modern economic growth: findings and reflections. The American economic review, v. 63, n. 3, p. 247-258, 1973.

KON, Anita. Nova economia política dos serviços. Perspectiva, 2015

LAPLANE, M. O complexo eletrônico na dinâmica industrial dos anos oitenta. 1992. Tese (Doutorado em Economia) - Programa de Pós-Graduação em Economia, Instituto de Economia, Universidade Estadual de Campinas, Campinas, 1992.

LESHER, M.; NORDÅS, H. K. Business services, trade and costs. OCDE libraly 2006.

LEWIS, W. A. Economic development with unlimited supplies of labour. The manchester school, v. 22, n. 2, p. 139-191, 1954.

LINDEN, G. et al Who captures value in a global innovation network?: the case of Apple's iPod. Communications of the ACM, v. 52, n. 3, p. 140-144, 2009.

MADDALA, G.S. Introduction to Econometrics.2nd edition, MacMillan, Nova York, 1992.

MCQUARRIE, Allan DR; TSAI, Chih-Ling. Regression and time series model selection. World Scientific, 1998.

MARKUSEN, J. R. Trade in producer services and in other specialised intermediate inputs. American Economic Review, v. 79, n. 85-95, 1989.

MILES, I.et al. Knowledge Intensive Business Services: Their Roles as Users, Carriers and Sources of Innovation. PREST, Manchester, 1994.

MILES, Ian et al. Knowledge-intensive business services: users, carriers and sources of innovation. European Innovation Monitoring System (EIMS) Reports, 1995.

MILES, Ian. Patterns of innovation in service industries. IBM Systems journal, v. 47, n. 1, p. 115-128, 2008.

MIOZZO, M.; SOETE, L.L.G. Internationalisation of services: a technological perspective. Third International Conference on Technology Policy and Innovation, Austin, USA, 1999.

MOTOHASHI, K. Information Technology Outlook. OECD, Paris. 1997.

MULLER, E.; ZENKER, A. Business services as actors of knowledge transformation: the role of KIBS in regional and national innovation systems. Research policy, v. 30, n. 9, p. 1501-1516, 2001.

NORDÅS, H. K., YUNHEE, K. Interaction between Goods and Services Trade: Case Studies. OCDE, Working Party of the Trade Committee. TAD/TC/WP(2013)15, June 4, 2013.

NORDÅS, H. K. The Impact of Services Trade Liberalisation on Trade in Non-Agricultural Products. OCDE Trade Policy Papers, v. 81, OCDE Publishing, 2008.

NORDÅS, H. K. Trade in goods and services: Two sides of the same coin? Economic Modelling, v. 27, n. 2, p. 496-506, 2010.

NORDÅS, Hildegunn K., and Kim; YUNHEE. Interaction between Goods and Services Trade: Case Studies. OCDE. Working Party of the Trade Committee. TAD/TC/WP(2013)15, June 4, 2013.

NÜBLER, I. A theory of capabilities for productive transformation: Learning to catch up. In: SALAZARXIRINACHS, JOSÉ, M.; NÜBLER, Irmgard; KOZUL-WRIGHT, Richard. Transforming economies: making industrial policy work for growth, jobs and development. INTERNATIONAL LABOUR OFFICE, 2014.

OCDE/OMC. Interconnected economies: benefiting from global value chains. PreliminaryVersion. Genebra, 2013.

OULTON, Nicholas. Must the growth rate decline? Baumol's unbalanced growth revisited. Oxford Economic Papers, v. 53, n. 4, p. 605-627, 2001. 
PARK, SE-HARK; CHAN, K. S.A cross-country input-output analysis of intersectoral relationships between manufacturing and services and their employment implications. World Development, v. 17, $\mathrm{n}$. 2, p. 199-212, 1989.

PAVITT, K. Sectoral patterns of technical change: towards a taxonomy and a theory. Research policy, v. 13, n. 6, p. 343-373, 1984.

PEREZ, Carlota. The double bubble at the turn of the century: technological roots and structural implications. Cambridge Journal of Economics, v. 33, n. 4, p. 779-805, 2009.

RODRIGUE, J. Transportation and the Geographical and Functional Integration of Global Production Networks. Growth and Change.Vol.37, n. 4, p. 510-25, 2006.

RODRIK, Dani. The past, present, and future of economic growth. Challenge, v. 57, n. 3, p. 5-39, 2014. SIQUEIRA, T. V. O setor de tecnologia da informação e telecomunicação no Brasil no período recente. Revista do BNDES, Rio de Janeiro, n. 14, n. 27, p. 213-260, jun. 2007.

SCHWARZ, Gideon et al. Estimating the dimension of a model. The annals of statistics, v. 6, n. 2, p. 461-464, 1978.

SHIN et al.The KPSS stationarity test as a unit root test. Economics Letters, v. 38, n. 4, p. 387-392, 1992.

SHIH, S. Millenium transformation: change management for new Acer. Aspire Academy Séries. 1992.

STOCK, J. H.; WATSON, M. W. Vector Autoregressions. Journal of Economic Perspectives, v. 15, n. 4, p. 101-115, 2001.

SUTCLIFFE, R. B. Industry and Under development. Addison-Wesley Publishing Company, 1971.

TIMMER, M. P.et al. Patterns of Structural Change in Developing Countries. In J. Weiss, \& M. Tribe (Eds.).Routledge Handbook of Industry and Development. (pp. 65-83). Routledge, 2015.

TODA, H. Y.; YAMAMOTO, T. Statistical inference in vector autoregressions with possibly integrated processes. Journal of econometrics, v. 66, n. 1, p. 225-250, 1995.

TRIPLETT, J. E.; BOSWORTH, B. Productivity in the US services sector: new sources of economic growth. Brookings Institution Press, 2004.

TRIPLETT, J. E.; BOSWORTH, B. Productivity measurement issues in services industries: Baumol's disease has been cured. Economic Policy Review, v. 9, n. 3, 2003.

WINDRUM, P; TOMLINSON, M. Knowledge-intensive services and international competitiveness: a four country comparison. Technology Analysis \& Strategic Management, v. 11, n. 3, p. 391-408, 1999. 